\title{
Silicon absorption and excretion is independent of age and sex in adults
}

\author{
Ravin Jugdaohsingh ${ }^{1,2 *}$, Supannee Sripanyakorn ${ }^{2,3}$ and Jonathan J. Powell ${ }^{1}$ \\ ${ }^{1}$ Elsie Widdowson Laboratory, MRC Human Nutrition Research, Fulbourn Road, Cambridge CB1 9NL, UK \\ ${ }^{2}$ Gastrointestinal Laboratory, King's College London, The Rayne Institute, St Thomas' Hospital, London SE1 7EH, UK \\ ${ }^{3}$ Faculty of Science and Technology, Loei Rajabhat University, Loei-Chiangkan Road, Amphoe Muang, Loei 42000, Thailand
}

(Submitted 14 September 2012 - Final revision received 5 December 2012 - Accepted 5 January 2013 - First published online 25 February 2013)

\section{Abstract}

Host factors influencing the absorption and excretion of $\mathrm{Si}$ are poorly understood, although previous murine and human studies have suggested that age, sex and oestrogen status may affect Si metabolism and thus function. Here, serum and urine samples were collected from twenty-six healthy adults at baseline and over a $6 \mathrm{~h}$ period following ingestion of $17 \cdot 4 \mathrm{mg} \mathrm{Si}$ (orthosilicic acid) and analysed by inductively coupled plasma optical emission spectrometry. Fasting baseline serum and urinary Si concentrations were marginally higher in older adults (51-66 years old) compared with young adults (20-47 years old); however, there was no difference in the absorption of Si into serum (overall profile, rate of $\mathrm{Si}$ appearance, peak concentration and time to peak) between the different adult groups. The rate of elimination of Si from serum did not significantly differ with age or sex, although serum concentration at $6 \mathrm{~h}$ was higher in older adults and significantly correlated with age $(r 0.5 ; P=0.01)$. There were, however, no significant differences in the excretion of Si into urine (a proxy for overall uptake) between the groups, averaging approximately $45 \%$. Oestradiol levels did not correlate with any of the above measures of Si. Thus, overall, host age and sex did not appear to markedly influence Si absorption or excretion in human adults and no correlations were found with serum oestradiol status. The marginally higher baseline and $6 \mathrm{~h}$ post-dose Si levels in older adults may reflect modestly impaired renal function and/or the loss of Si from connective tissues with ageing.

Key words: Silicon metabolism: Orthosilicic acid: Pre- and postmenopausal women: Young and older men: Oestrogen status

Mounting evidence suggests an important role for dietary Si in connective tissue health. Indeed, in the 1970s, dietary Si deficiency studies in laboratory animals reported stunted growth and profound defects in bone and other connective tissues, and led to the suggestion of a key role for Si in normal growth and development in higher animals ${ }^{(1,2)}$. However, whether Si really has an essential role in mammals (including humans) has not since been established, although, recently, we reported that higher dietary Si intake is associated with higher bone mineral density in men and pre-menopausal women and in postmenopausal women taking hormone replacement therapy (HRT) but not in postmenopausal women not taking $\mathrm{HRT}^{(3,4)}$. These findings suggest an association between dietary Si and oestrogen status (see Jugdaohsingh et al. ${ }^{(3)}$ and Macdonald et $a l .{ }^{(4)}$; also see below). If Si has a biological role, its mechanism of action is not known, but in vitro cell culture studies and analytical studies have implied its functionality in collagen synthesis and/or stabilisation ${ }^{(5,6)}$.

Recent work has also identified significant dietary sources of Si and determined its absorption in human volunteers ${ }^{(7-9)}$. As with other dietary minerals, the chemical speciation of ingested
$\mathrm{Si}$ is a major determinant of its availability for absorption from the intestinal lumen. $\mathrm{Si}$ is absorbed as orthosilicic acid (OSA) $\left(\mathrm{Si}(\mathrm{OH})_{4}\right)$, so dietary sources that deliver this form, or easily digested precursors to this form, are well absorbed (approximately $50 \%$ in adults). However, host factors that influence $\mathrm{Si}$ uptake (absorption) and its excretion remain poorly understood: a study in rats has suggested that host age and sex may affect the absorption and metabolism of Si mainly through differences in endogenous sex and endocrine hormones ${ }^{(10)}$. Such an observation may be important and could, for example, explain the lack of association between dietary Si intake and bone mineral density in postmenopausal women not taking HRT, due to low oestrogen status, compared with the significant positive associations in pre-menopausal women (high oestrogen status), postmenopausal women taking HRT and, to a lesser extent, in men where aromatase activity converts some testosterone to oestrogen ${ }^{(3,4)}$. We have, therefore, determined whether the metabolism of $\mathrm{Si}$ is dependent on age and sex, by comparing the serum absorption profiles and urinary excretion of Si between young and older men and between pre- and postmenopausal women following ingestion of $17.4 \mathrm{mg} \mathrm{Si}$, in the

Abbreviations: HRT, hormone replacement therapy; OSA, orthosilicic acid; RM, repeated measures; UHP, ultra-high purity.

* Corresponding author: R. Jugdaohsingh, fax +44 1223 437515, email ravin.jugdaohsingh@mrc-hnr.cam.ac.uk 
form of OSA. The $17 \cdot 4 \mathrm{mg}$ Si dose represents about $40-100 \%$ of daily dietary $\mathrm{Si}$ intake in the Western world and presents a feasible Si intake from a high Si-containing meal (e.g. containing green beans and a pint of beer ${ }^{(8)}$.

\section{Materials and methods}

\section{Materials}

Ultra-high-purity (UHP) water $(18 \mathrm{M} \Omega / \mathrm{cm})$ was from an Elga water purifier (Elga Limited). Hydrochloric acid ( $5 \mathrm{~mol} / \mathrm{l})$, concentrated basic sodium silicate solution $(14 \%(\mathrm{w} / \mathrm{v}) \mathrm{NaOH}$ and $27 \%(\mathrm{w} / \mathrm{v}) \mathrm{SiO}_{2}$ ) and $\mathrm{Si}$ inductively coupled plasma (ICP) stock standard solution ( $9800 \mathrm{mg} \mathrm{Si} / \mathrm{l}$ ) were from Aldrich Chemical Company. Nitric acid $(65 \%(\mathrm{w} / \mathrm{v})$ pro analysi plus $\mathrm{HNO}_{3}$ ) was high purity from Fluka Limited. Polypropylene Mauser bottles ( 2.5 litres), for urine collection, were from Aldrich Chemical Company. Polypropylene transport tubes $(10 \mathrm{ml})$, for blood collection, were from Sarstedt Limited. Other polypropylene plastic wares were from VWR International Limited, Aldrich Chemical Company or Greiner Bio-One Limited. The DRG Estradiol ELISA kit (EIA-2693) was from DRG International, Inc. A creatinine assay kit (Metra Biosystems, Inc.), used for the quantification of creatinine in urine samples, was purchased from Technoclone Limited. Inductively coupled plasma optical emission spectrometry (Jobin Yvon, JY24; Instruments SA) and the UHP water supply were housed in a class $\mathrm{J}$ clean-air room to reduce potential sources of contamination.

\section{Subjects}

A total of twenty-nine subjects (Table 1) were recruited by circular email from King's College London and posters in public places. However, only twenty-six subjects completed the study: eight young men ( $<47$ years old); five older men $(>50$ years old); nine pre-menopausal women; four postmenopausal women. Subjects were healthy and not on any medications, treatments or supplements (including Si). Subjects were excluded if they were under 18 years of age, pregnant and lactating women or unable to follow simple instructions. Postmenopausal women were classified as women having ceased menstruation for at least 1 year. The average length of cessation was 7.4 (SD 6.4) years. Men were age-matched with the women recruited. The present study was conducted according to the guidelines laid down in the Declaration of Helsinki, and ethical approval for the study was obtained from King's College London Local Research Ethics Committee. All subjects gave signed written informed consent before the commencement of the study.

\section{Sample size}

This was a pilot study. No previous study had compared Si metabolism in young and older adult men and women, although one study has compared baseline serum Si concentrations in different age groups ${ }^{(11)}$. Urinary excretion of $\mathrm{Si}$, used as a surrogate marker of absorbed $\mathrm{Si}^{(7,12,13)}$, was used

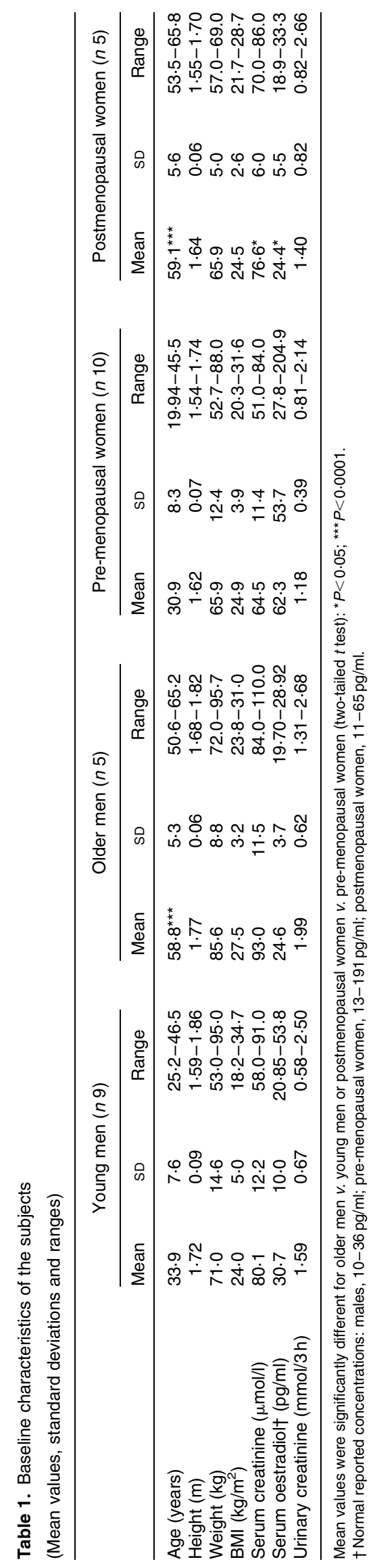


to estimate the sample size required for the present study. A mean of $55 \%$ and a standard deviation $(\sigma)$ of $9.4 \%$ were estimated for the average percentage excretion of urinary $\mathrm{Si}^{(13)}$. Consequently, five completed subjects were estimated to be the minimum number required in each group, at $90 \%$ power and 95\% significance, to observe a difference of $20 \%$ between subjects after ingestion of the OSA solution.

\section{Study design}

The study was conducted over $2 \mathrm{~d}$. Subjects were asked to refrain from ingesting foods known to be of high Si content (green beans, cereals and their products including beer, rice, bananas and dried fruits) $24 \mathrm{~h}$ before the commencement of the study and during the two study days.

Day 1. After an overnight fast, subjects emptied their bladder and then collected a $3 \mathrm{~h}$ urine collection, for determination of baseline urinary Si output. Subjects consumed only UHP water of low Si content over this $3 \mathrm{~h}$ period. Thereafter, they were allowed to continue with their normal eating patterns but avoiding high Si-containing foods.

Day 2. The next day, the same subjects fasted from overnight, emptied their bladder and had an intravenous cannula inserted into a forearm vein and two $10 \mathrm{ml}$ blood samples were collected for baseline serum Si measurement. Subjects then consumed $600 \mathrm{ml}$ of UHP water containing $17.4 \mathrm{mg} \mathrm{Si}$ (29 $\mathrm{mg} \mathrm{Si} / 1$ as OSA) and further blood samples $(10 \mathrm{ml})$ were collected over a $6 \mathrm{~h}$ period; initially at half-hourly intervals for $2 \mathrm{~h}$ and then at one-hourly intervals for the remaining $4 \mathrm{~h}$. Urine was also collected over this period as two $3 \mathrm{~h}$ collections. Subjects remained fasted over the $6 \mathrm{~h}$ period, ingesting only UHP water of low Si content. Thereafter, subjects continued with their normal eating patterns.

\section{Orthosilicic acid solution}

The OSA solution for ingestion was prepared as described previously ${ }^{(13)}$ by dilution in UHP water (to $1 \mathrm{mmol} / \mathrm{l}=28 \mathrm{mg} \mathrm{Si} / \mathrm{l}$ ), and then neutralisation (to $\mathrm{pH} 7$ ), of the concentrated (about $7 \mathrm{~mol} / \mathrm{l}$ ) basic (pH approximately 14) sodium silicate solution.

\section{Blood collections and preparation}

Blood samples were left to stand at room temperature for $1 \mathrm{~h}$ to clot and then centrifuged at $3000 \mathrm{rpm}$ for $10 \mathrm{~min}$ at $4^{\circ} \mathrm{C}$. Sera were then separated into $10 \mathrm{ml}$ polypropylene tubes and stored frozen at $-20^{\circ} \mathrm{C}$. Duplicate aliquots $(0.5 \mathrm{ml})$ of baseline serum were also collected into cryovials and stored at $-70^{\circ} \mathrm{C}$ for measurement of circulating oestradiol concentrations. All steps in the preparation of the blood samples were carried out in a class $C$ laminar clean-air cabinet that was housed in a class J clean-air room. In addition, for each subject, $4 \mathrm{ml}$ whole blood collected at baseline, before ingestion of the dose solution, was sent to the Department of Haematology (St Thomas' Hospital) for analysis of serum creatinine concentrations to assess renal function.

\section{Urine collection and preparation}

Urine samples $(3 \mathrm{~h}$ baseline on day 1 and $0-3 \mathrm{~h}$ and $3-6 \mathrm{~h}$ post-dose on day 2) were collected in pre-weighed, pre-cleaned 2.5-litre polypropylene Mauser bottles. After thorough mixing, a $15 \mathrm{ml}$ aliquot was collected into a $30 \mathrm{ml}$ polypropylene bottle and diluted with an equivalent volume of $0.7 \%(\mathrm{v} / \mathrm{v}) \mathrm{HNO}_{3}$ before storage at $4{ }^{\circ} \mathrm{C}$ for later $\mathrm{Si}$ analysis.

\section{Analyses}

Total silicon. Serum, urine and samples of the dose solution were analysed for total Si concentrations by inductively coupled plasma optical emission spectrometry at $251.611 \mathrm{~nm}$ with a flow rate of $1 \mathrm{ml} / \mathrm{min}$ and using pooled sample-based standards as described previously ${ }^{(12-14)}$. Analysis was by peak profile with a window size of $0 \cdot 1 \mathrm{~nm}$ with fifty-four increments per profile and an integration time of $0.3-0.5 \mathrm{~s}$. Serum samples were thawed and diluted 1:5 with $0.7 \%(\mathrm{w} / \mathrm{v})$ $\mathrm{HNO}_{3}$ before analysis. Urine samples were incubated overnight at $40^{\circ} \mathrm{C}$ in an oven to resolubilise any urinary precipitates produced during storage and then cooled to room temperature before analysis ${ }^{(15)}$.

Urinary creatinine. Urinary creatinine was measured inhouse, in the diluted urine samples (baseline, $0-3$ and 3-6h), using a creatinine kit from Metra Biosystems, Inc. This is a quantitative colorimetric assay based on the modified Jaffe method, where alkaline picrate forms a coloured complex with creatinine. The diluted urine samples were mixed and left to settle for $15-20 \mathrm{~min}$ to eliminate any precipitates. An aliquot was then removed and further diluted (1:40 with UHP water), as were the standards and controls from the kit. The intra- and inter-assay CV were 1.65 and $4.32 \%$, respectively.

Oestrogen status. Baseline serum samples were analysed in duplicate to determine circulating oestrogen concentrations using the DRG Estradiol ELISA kit (DRG International, Inc.). The assay is based upon competition between oestradiol in the serum sample and oestradiol (conjugated with horseradish peroxidase) from the kit for the binding sites (polyclonal oestradiol antiserum) on the wells of the ELISA plate. The dynamic assay range is $9.7-2000 \mathrm{pg} / \mathrm{ml}$ and shows no cross-reactivity with other sex hormones/metabolites. The intra- and inter-assay CV were $2 \cdot 7-6.8 \%$ and $6.7-9.4 \%$, respectively.

\section{Statistical analysis}

Results are expressed as means and standard deviations unless otherwise stated. An independent (unpaired)-samples twotailed $t$ test was used to compare differences between young and old men, between pre- and postmenopausal women and between men and women. A $P$ value of $\leq 0.05$ was considered as significant. As this was a pilot study and the first of its type, we report simple $P$ values and have not attempted to correct for multiple testing. Repeated-measures (RM) ANOVA was used to compare the serum and urinary Si profiles. Pearson's correlation (with two-tailed $t$ test) was used to test for correlations between subject characteristics and serum 
and urinary Si parameters. Statistical analysis was conducted using SPSS 18 for Windows (PASW Statistics 18; SPSS, Inc.).

\section{Results}

\section{Subject characteristics}

The subject characteristics are described in Table 1. Mean serum creatinine levels appeared to be higher in the older adult groups (older men and postmenopausal women) compared with the young adult groups (young men and pre-menopausal women), but this was only significant between post- and pre-menopausal women $(P<0.05)$. Serum creatinine was positively correlated with age $(r 0.37$, $P=0.05$; RM-ANOVA), and although mean urinary creatinine excretion was higher in the older adult groups, compared with the young adult groups in the present study (Table 1), this was not significant. Serum oestradiol was lower in the older adult groups compared with the young adult groups, and, again, this was only significant between post- and premenopausal women $(P=0 \cdot 05)$. Serum oestradiol was also inversely correlated with age $(r-0.52, P=0.004)$.
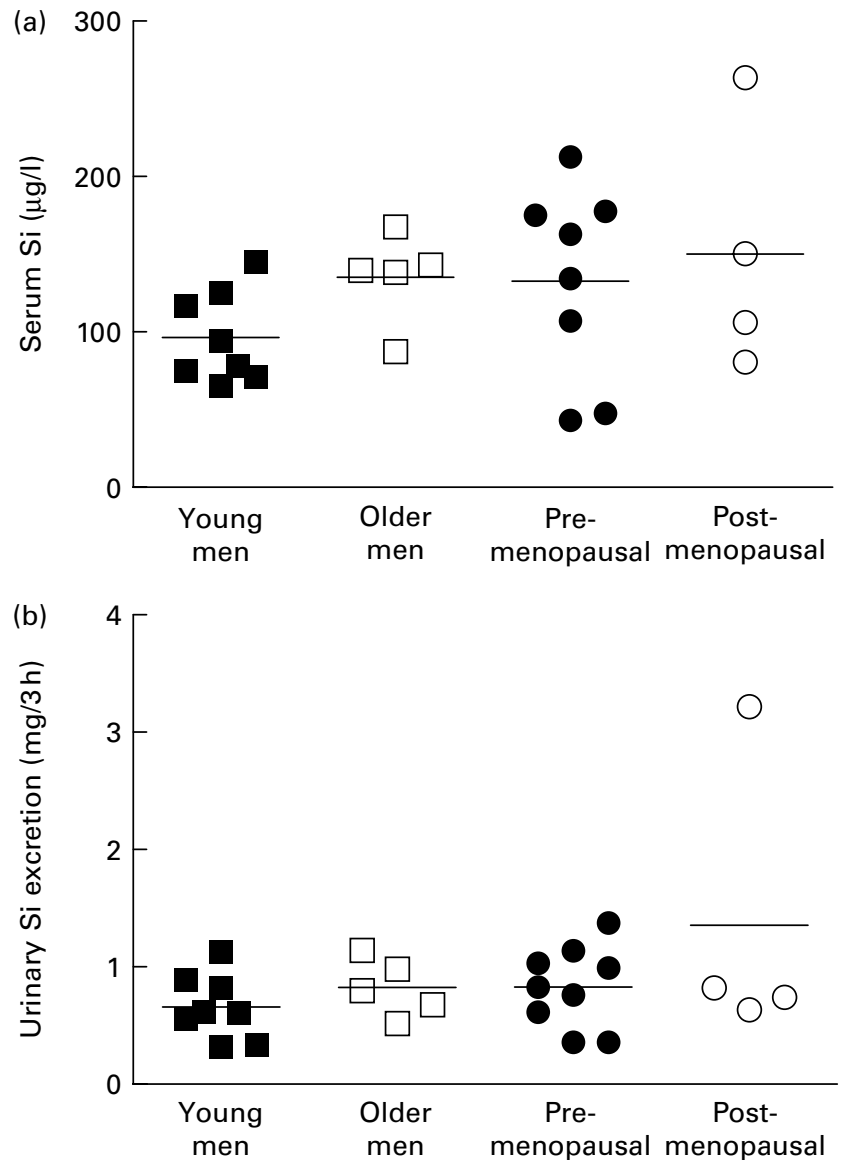

Fig. 1. Fasting (baseline) (a) serum and (b) urinary silicon levels in young men (mean age 34 years, $n 8$; $\mathbf{\square}$ ), older men (mean age 59 years, $n 5 ; \square$ ), pre-menopausal women (mean age 31 years, $n 8$ (serum) and $n 9$ (urine); $\bullet$ ) and postmenopausal women (mean age 59 years, $n 4$; $\bigcirc$ ). Levels are shown for each subject and the horizontal bars show mean levels within each adult group. Fasting serum silicon was significantly higher in older men compared with young men $(P=0.04$; independent-samples $t$ test).

\section{Fasting silicon concentrations}

Mean fasting serum Si levels appeared to be higher in the older adult groups compared with the young adult groups; especially this was significant $(P=0.04)$ between older men and young men: 135 (sD 29) $\mu \mathrm{g} / 1$ in older men $v .96$ (sD 29) $\mu \mathrm{g} / 1$ in young men and 150 (SD 81) $\mu \mathrm{g} / 1$ in postmenopausal women $v .133$ (SD 62) $\mu \mathrm{g} / 1$ in pre-menopausal women (Fig. 1(a)). Similarly, mean fasting (baseline $3 \mathrm{~h}$ ) urinary Si excretion was higher in the older adult groups compared with the young adult groups (0.82 (SD 0.25) $\mathrm{mg} / 3 \mathrm{~h}$ in older men $v \cdot 0.66(\mathrm{sD} 0.28) \mathrm{mg} / 3 \mathrm{~h}$ in young men and $1.35(\mathrm{SD} 1.25) \mathrm{mg} / 3 \mathrm{~h}$ in postmenopausal women $v \cdot 0.83(\mathrm{SD} 0.35) \mathrm{mg} / 3 \mathrm{~h}$ in pre-menopausal women; Fig. 1(b)), but this was not significant. No significant difference in serum Si concentration or fasting urinary Si excretion was found between men and women $(P=0.203$ and $P=0.225$, respectively) on combining the appropriate groups.

No significant correlation was obtained between fasting serum or urinary $\mathrm{Si}$ and the other subject characteristics, including age and serum oestradiol concentrations. However, fasting serum and urinary Si levels were significantly positively correlated $(r 0.76, P=0.00005$; Fig. 2$)$ as expected ${ }^{(12)}$.

\section{Silicon absorption}

Overall, no significant difference in serum $\mathrm{Si}$ absorption profile was found between young and older men, or between pre- and postmenopausal women ( $P=1.0$ and 0.91 , respectively, RM-ANOVA; Fig. 3), although the peak in serum Si concentration was seen marginally earlier $(P=0.04)$ in young men $(1.13$ (SD 0.23$) \mathrm{h}$, range $1-1.5 \mathrm{~h})$ compared with older men ( 1.5 (SD 0.35) h, range $1-2 \mathrm{~h}$ ) (Fig. 3(a)). Peak Si concentration, the AUC and the slope/gradient of the absorption (Si-IN) and elimination (Si-OUT) phases of the serum Si absorption profile were not significantly different between young and older men $(P=0.4,1 \cdot 0,0.3$ and 0.5 , respectively) or between preand postmenopausal women $(P=0 \cdot 7,0 \cdot 4,0 \cdot 2$ and $0 \cdot 7$, respectively). The apparent visible difference in the elimination

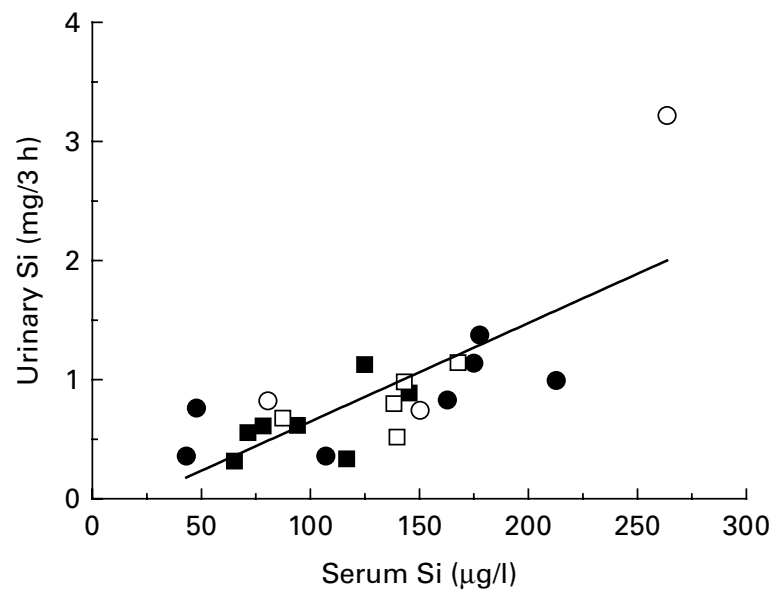

Fig. 2. Correlation between fasting baseline serum silicon concentration and fasting baseline (3h) urinary silicon excretion: young men ( $\square$ ); older men $(\square)$; pre-menopausal women $(\bullet)$; postmenopausal women $(\bigcirc) . r \quad 0.76$, $P=0.00005$ (Pearson's correlation with two-tailed $t$ test). 

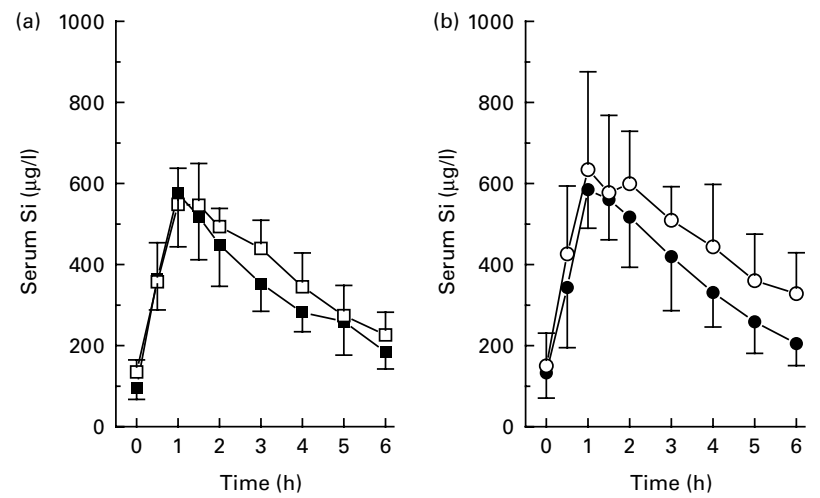

Fig. 3. Serum silicon profiles for (a) young and older men and (b) pre- and postmenopausal women, following ingestion of $17.4 \mathrm{mg}$ silicon, in the form of orthosilicic acid, in high-purity water. Values are means of eight young men $(\square)$, five older men $(\square)$, eight pre-menopausal women $(\bullet)$ and four postmenopausal women $(\bigcirc)$, with standard deviations represented by vertical bars. There was no significant difference in serum absorption between the groups, nor was the apparent difference in the elimination phase of the serum silicon curves between pre- and postmenopausal women significant. Serum silicon concentration at $6 \mathrm{~h}$ was significantly higher in postmenopausal women compared with pre-menopausal women $(P=0.018$; independent-samples $t$ test)

phase of the serum Si profile between pre- and postmenopausal women was also not significantly different ( $P=0 \cdot 7$; Fig. 3(b)). However, serum Si concentration at $6 \mathrm{~h}$ (the last collection time point $)$ was significantly higher $(P=0.018)$ in postmenopausal women compared with pre-menopausal women, and the mean value was higher in older men compared with young men but not significantly so $(P=0 \cdot 147)$.

On combining the groups, no significant difference was found for the absorption of $\mathrm{Si}$ into serum between men and women $(P=0 \cdot 203$; RM-ANOVA $)$. Serum Si concentration at $6 \mathrm{~h}$ was significantly higher $(P=0 \cdot 01)$ in older adults compared with young adults and significantly correlated with age $(r 0 \cdot 49$, $P=0 \cdot 013)$. No significant correlations were obtained for serum oestradiol with any of the serum parameters measured.

\section{Urinary silicon excretion}

There was no significant difference in the urinary Si excretion profile/pattern, following ingestion of OSA, between young and older men $(P=1 \cdot 0)$, between pre- and postmenopausal women $(P=1.0)$ or between men and women $(P=0.72)$ (Fig. 4(a) and (b)). Thus, the excretion of Si into urine $(0-6 \mathrm{~h}$, post-dose), as a percentage of the ingested dose (17.4 mg Si), was similar in all the four adult groups (Fig. 5). No significant correlations were seen with serum oestradiol concentrations

\section{Urinary creatinine excretion}

Urinary excretion of creatinine was also measured following ingestion of OSA (Fig. 4(c) and (d)). Mean urinary creatinine excretion was higher in postmenopausal women compared with pre-menopausal women (Fig. 4(d)), but not significantly so $(P=1.0$; RM-ANOVA), and was significantly higher in older men compared with young men ( $P=0.05$; RM-ANOVA), especially in the $0-3 \mathrm{~h}$ post-dose collection $(P=0 \cdot 004)$.
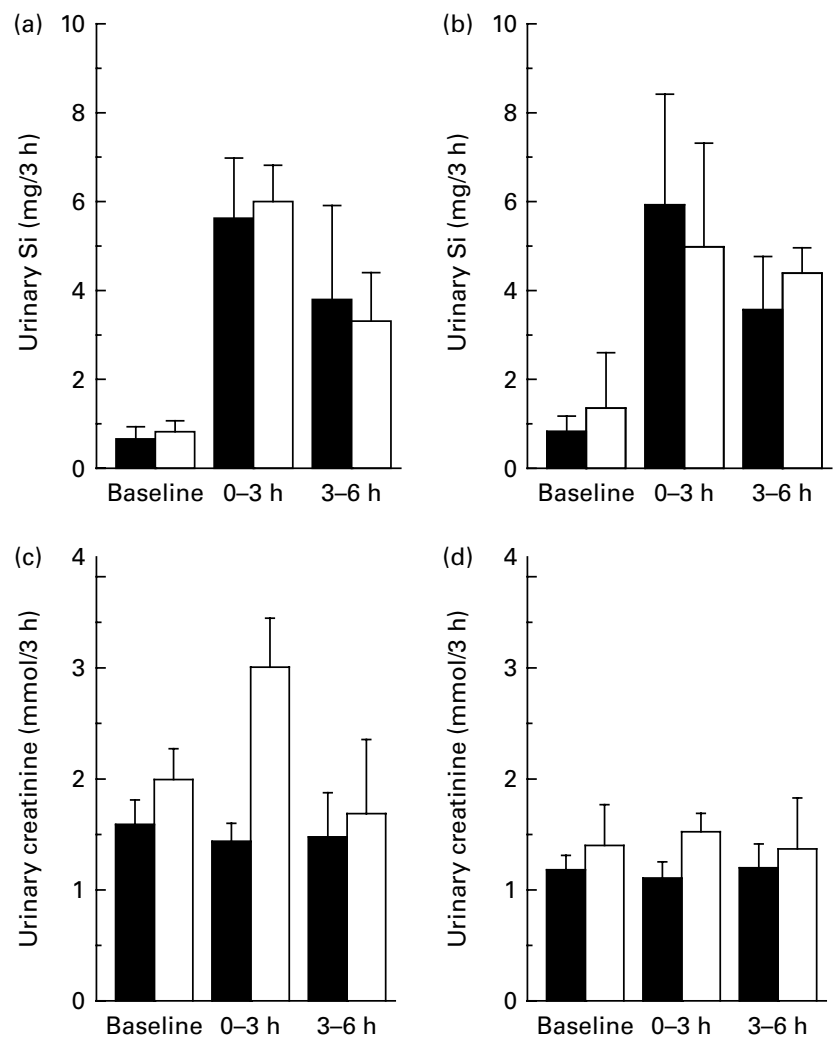

Fig. 4. Urinary silicon excretion in (a) young and older men and (b) pre- and postmenopausal women following ingestion of $17.4 \mathrm{mg}$ silicon, in the form of orthosilicic acid, in high-purity water. There was no significant difference in urinary silicon excretion between the four groups. Urinary creatinine excretion (c) in young and older men and (d) pre- and postmenopausal women following ingestion of the orthosilicic acid solution. Urinary creatinine excretion was significantly higher in older men compared with young men $(P=0.05$; repeated-measures ANOVA), especially in the $0-3 \mathrm{~h}$ post-dose collection $(P=0.004$; independent-samples $t$ test). Values are means of eight young men $(\square)$, five older men $(\square)$, nine pre-menopausal women $(\boldsymbol{\square})$ and four postmenopausal women ( $\square$ ), with standard deviations (Figs. 4(a) and (b)) or standard errors (Figs. 4(c) and (d)) represented by vertical bars.

\section{Discussion}

The present study suggests that the gastrointestinal uptake of $\mathrm{Si}$ into serum and its excretion into urine, in adults, is not influenced by age, sex or concomitant oestrogen status. Si absorption into serum was similar between the four adult groups, albeit the peak in serum Si concentration appeared to be slightly earlier in young adults (young men and pre-menopausal women) compared with older adults (older men and postmenopausal women) and also appeared to be cleared slightly more quickly (by comparison of $6 \mathrm{~h}$ post-ingestion time points; see below). There was no significant difference in the slope of the absorption phase of the serum Si profile, peak serum Si concentration or AUC, suggesting that gastrointestinal uptake of Si (OSA) was similar between the adult groups. An apparent (visual) difference in the elimination of $\mathrm{Si}$ from serum in older adults $v$. young adults (Fig. 3), especially between postmenopausal women and pre-menopausal women, was not borne out on analysis of the slopes of the 


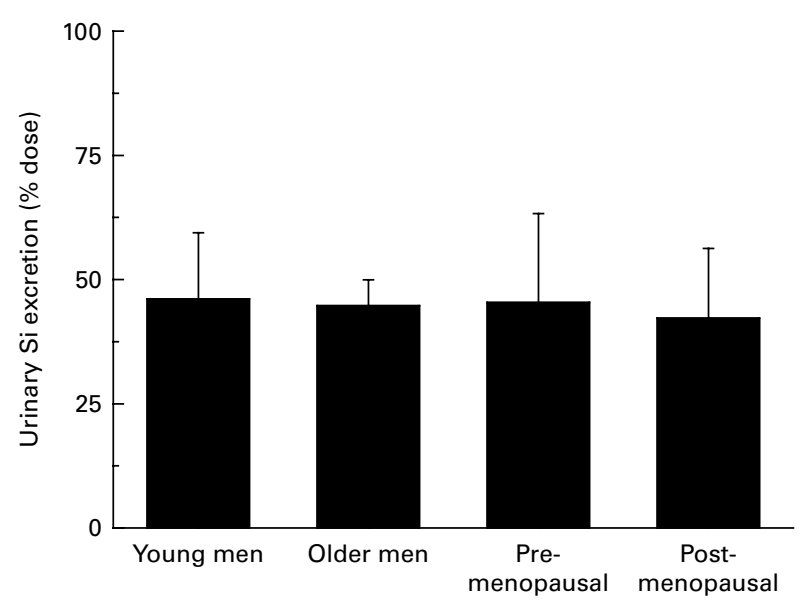

Fig. 5. Urinary silicon excretion over the $0-6 \mathrm{~h}$ post-dose period as a percentage of the ingested dose (17.4 mg silicon) in young and older men and in pre- and postmenopausal women. There was no significant difference between the groups. Values are means of eight young men, five older men, nine pre-menopausal women and four postmenopausal women, with standard deviations represented by vertical bars.

elimination phase of the Si profiles. However, the higher serum Si concentration at $6 \mathrm{~h}$ in older adults was significant and positively correlated with age. Analysis of the amount of Si excreted into urine over the $6 \mathrm{~h}$ period did not show a significant difference in Si output between the four adult groups and mean urinary $\mathrm{Si}$ excretions, as a percentage of the ingested dose, were similar, being approximately $45 \%$.

It was noted in the present study that baseline serum creatinine was higher in the older adult groups compared with the young adult groups and positively correlated with age $(r 0.37$, $P=0.05$; RM-ANOVA), implying that renal function may be slightly impaired in older adults as reported previously ${ }^{(16,17)}$. However, urinary excretion of creatinine did not confirm this (i.e. there was no reduction in creatinine output in older adults $)^{(16,17)}$ and, in fact, appeared to be higher in postmenopausal women and was significantly higher in older men $(P=0.05)$, compared with pre-menopausal women and young men, respectively. The higher serum and urinary creatinine levels in older men compared with young men are, therefore, probably due to higher mean weight and BMI (Table 1) in the former group and, especially, enhanced muscle wasting with age.

Contrary to the published findings in rats, where sex and endocrine hormones have been reported to affect the metabolism of $\mathrm{Si}^{(10)}$, no significant correlation was obtained here with fasting serum oestradiol concentration for any of the serum and urinary parameters measured, even though serum oestradiol was inversely correlated with age $(r-0.5$, $P=0.004)$ and serum Si concentration at $6 \mathrm{~h}$ was also positively correlated with age. Serum oestradiol was measured at one time point in the present study, in the fasting baseline serum samples, and so, especially for pre-menopausal women, may not accurately reflect mean circulating concentrations, since these will be dependent on the stage of the menstrual cycle. Indeed, a large variation in serum oestradiol concentration was found in pre-menopausal women and also in young men (Table 1), which may be the cause of the lack of associations. In adult rats, Charnot \& Pérès ${ }^{(10)}$ reported that ageing reduced the absorption of $\mathrm{Si}$ administered as sodium silicate and also reduced tissue $\mathrm{Si}$ levels (except calcified tissue which increased), most notably in female rats and less so in male rats. They have suggested that this may be due to the decline in sex and endocrine hormones with ageing, which occurs especially in females ${ }^{(10)}$. Different study designs to the one described herein may be needed to reveal such hormonal effects on Si absorption in human subjects. Alternatively, there is no such hormonal effect on Si absorption in humans, and the reported oestradiol-Si interaction in human subjects $^{(3,4)}$ is restricted to altered tissue incorporation of Si.

We did, however, confirm that fasting baseline serum and urine Si concentrations correlate significantly $(r 0.8$, $P=0.00005)$, as reported previously ${ }^{(12)}$, and we also found a trend for higher baseline fasting serum and urinary Si concentrations in older adults compared with younger adults, and higher concentrations in women compared with men. Overall, our serum Si concentrations are comparable with those in the literature, for example Van Dyck et $a l^{(11)}: 115$ (SD 51) $\mu \mathrm{g} / \mathrm{l}$ in young men $(19-39 \text { years, } n 31)^{(11)} v .96$ (sD 29) $\mu \mathrm{g} / 1$ in the present study; 129 (SD 57) $\mu \mathrm{g} / 1$ in older men $(40-60 \text { years, } n 30)^{(11)}$ $v .135(\mathrm{SD} 29) \mu \mathrm{g} / \mathrm{l}$ in the present study; 126 (SD 73) $\mu \mathrm{g} / 1$ in young, non-pregnant women $(19-39 \text { years, } n 34)^{(11)} v .133$ (SD 62$) \mu \mathrm{g} / \mathrm{l}$ in the present study; 154 (SD 65) $\mu \mathrm{g} / \mathrm{l}$ in older women $(40-60 \text { years, } n 31)^{(11)} v .150$ (SD 81) $\mu \mathrm{g} / 1$ in the present study. Taken together, it is possible therefore that either (1) Si is lost from connective tissues with ageing, rather as creatinine is from muscle, or (2) Si is a more sensitive marker than creatinine for modestly impaired renal function. We favour mostly possibility (1) because Si absorption and excretion appeared to be broadly similar between all groups and only baseline and $6 \mathrm{~h}$ serum levels were really affected. However, an interaction between (1) and (2), too complex/subtle to be dissected out herein, is perfectly possible.

We recognise that there was a relatively small number of subjects in the present study, although organisational and analytical workloads were not small, but we also believe 'fit for purpose' conclusions can be drawn:

(1) Oestradiol status (as measured or inferred from age and sex) does not obviously affect Si absorption or excretion in humans, although effects on tissue loading of Si cannot be determined from the present data.

(2) Age and sex per se do not obviously affect Si absorption or excretion in human adults aged $<66$ years old.

(3) There are probably small changes in (increases in) baseline serum Si levels with ageing in adults as reported previously $^{(10)}$. The unloading of $\mathrm{Si}$ from connective tissues with ageing should now be investigated, although subtle changes in renal function may also have an impact on these observations.

In conclusion, here we report that age, sex and oestradiol status do not affect $\mathrm{Si}$ absorption or excretion in adults $<66$ years old. These results suggest that the lack of association between dietary $\mathrm{Si}$ intake and bone mineral density in postmenopausal women not taking HRT, compared with the significant positive associations seen in pre-menopausal 
women, postmenopausal women taking HRT or men ${ }^{(6,7)}$, is not due to the differences in Si absorption but, more probably, due to differences in the utilisation of $\mathrm{Si}$ at the cellular level, possibly mediated by oestradiol, and this requires further investigation.

\section{Acknowledgements}

The present study was supported by the Medical Research Council (grant no. MC_US_A090_0008/Unit Programme number U1059). We thank the charitable foundation of the Institute of Brewing and Distilling for the running costs. We thank Sarah Agar and Lucy Pearson for their help in conducting this study. The authors' contributions were as follows: S. S., R. J. and J. J. P. contributed to the concept and design of the study; S. S. and R. J. were responsible for the experimental and analytical aspects of the manuscript; S. S. was the study coordinator; S. S., R. J. and J. J. P. were involved in the data interpretation, presentation and writing of the first draft of the manuscript. All authors declare that they have no conflict of interest.

\section{References}

1. Carlisle EM (1972) Silicon: an essential element for the chick. Science 178, 619.

2. Schwarz K \& Milne DB (1972) Growth promoting effects of silicon in rats. Nature 239, 333-334.

3. Jugdaohsingh R, Tucker KL \& Qiao N (2004) Silicon intake is a major dietary determinant of bone mineral density in men and pre-menopausal women of the Framingham Offspring Cohort. J Bone Mineral Res 19, 297-307.

4. Macdonald HM, Hardcastle AE, Jugdaohsingh R, et al. (2012) Dietary silicon interacts with oestrogen to influence bone health: evidence from the Aberdeen Prospective Osteoporosis Screening Study. Bone 50, 681-687.

5. Sripanyakorn S, Jugdaohsingh R, Thompson RPH, et al. (2005) Dietary silicon and bone health. Nutr Bull 30, 222-230.
6. Jugdaohsingh R (2007) Silicon and bone health. I Nutr Health Aging 11, 99-110.

7. Jugdaohsingh R, Anderson SH, Tucker KL, et al. (2002) Dietary silicon intake and absorption. Am J Clin Nutr $\mathbf{7 5}$, 887-893.

8. Powell JJ, McNaughton SA, Jugdaohsingh R, et al. (2005) A provisional database for the silicon content of foods in the United Kingdom. Br J Nutr 94, 804-812.

9. McNaughton SA, Bolton-Smith C, Mishra GD, et al. (2005) Dietary silicon intake in post-menopausal women. $\mathrm{Br} J$ Nutr 94, 813-817.

10. Charnot Y \& Pérès G (1971) Change in the absorption and tissue metabolism of silicon in relation to age, sex and various endocrine glands. Lyon Med 13, 85 .

11. Van Dyck K, Robberecht $\mathrm{H}$, Van Cauwenbergh $\mathrm{R}$, et al. (2000) Indication of silicon essentiality in humans. Serum concentrations in Belgian children and adults, including pregnant women. Biol Trace Elem Res 77, 25-32.

12. Reffitt DM, Jugdaohsingh R, Thompson RPH, et al. (1999) Silicic acid: its gastrointestinal uptake and urinary excretion in man and effects on aluminium excretion. J Inorg Biochem 76, 141-147.

13. Sripanyakorn S, Jugdaohsingh R, Elliott H, et al. (2004) The silicon content of beer and its bioavailability in healthy volunteers. Br J Nutr 91, 403-409.

14. Burden TR, Powell JJ \& Thompson RPH (1995) Optimal accuracy, precision and sensitivity of inductive coupled plasma optical emission spectrometry: bioanalysis of aluminium. J Anal Atom Spectrom 10, 259-266.

15. Burden TJ, Whitehead MW, Thompson RP, et al. (1998) Preparation of urine samples for trace metal determination: a study with aluminium analysis by inductively coupled plasma optical emission spectroscopy. Ann Clin Biochem 35, 245-253.

16. Rowe JW, Andres R, Tobin JD, et al. (1976) The effect of age on creatinine clearance in men: a cross-sectional and longitudinal study. J Gerontol 31, 155-163.

17. Musso CG \& Oreopoulos DG (2011) Aging and physiological changes of the kidneys including changes in glomerular filtration rate. Nephron Physiol 119, Suppl. 1, p1-p5. 